\title{
A POÉTICA DO JORNAL OITOCENTISTA: UM COTEJO ENTRE EUGÈNE PELLETAN E MACHADO DE ASSIS
}

\author{
MUSSULINI, Dayane ${ }^{1}$
}

RESUMO: A existência de uma poética do jornal oitocentista pode ser pensada não só a partir da elaboração de uma retórica semelhante entre os escritores do século XIX, que emprestavam estratégias ficcionais aos periódicos em que colaboravam e vice-versa, como também, segundo demonstra Lúcia Granja (2018), por meio de intertextualidades (citações, alusões, pastiches, paródias e demais referências) comuns entre autores e obras. Além disso, tais reincidências apontavam para leituras compartilhadas e trocadas entre os diferentes continentes, bem como contribuíam para a formação de certo gosto cultural, de acordo com as escolhas dos jornalistas. Percurso semelhante é reconhecível entre Eugène Pelletan, escritor e jornalista francês, e Machado de Assis. Ambos defenderam o jornal enquanto espaço democrático e liberal para a transmissão de ideias. A partir dessa aproximação, procederemos ao cotejo entre os dois autores, a fim de verificar como o assunto e as estratégias retóricas assemelham-se, configurando uma prática então em voga, e também como se diferenciam, tendo em vista as particularidades de Machado de Assis.

PALAVRAS-CHAVE: Machado de Assis, Eugène Pelletan, imprensa periódica, crítica literária, progresso.

\section{LA POÉTIQUE DU JORNAL AU XIX ${ }^{\mathrm{e}}$ SIÈCLE : UNE COMPARATION ENTRE EUNGÈNE PELLETAN ET MACHADO DE ASSIS}

RÉSUMÉ : L'existence d'une poétique du journal au XIX ${ }^{\mathrm{e}}$ siècle peut être pensée non-seulement à partir de l'élaboration d'une rhétorique semblable chez les écrivains du XIX ${ }^{\mathrm{e}}$, lesquels empruntaient des stratégies ficcionelles aux périodiques dans lesquels ils collaboraient et vice-versa, aussi bien que, selon démontre Lúcia Granja (2018), grâce aux intertextualités (des citations, allusions, parodies, pastiches et

\footnotetext{
${ }^{1}$ Doutora em Letras pela Faculdade de Ciências e Letras de Assis (UNESP). Docente de Língua Portuguesa do Ensino Fundamental II e Ensino Médio da escola SESI Assis. E-mail: daymussulini @ gmail.com.
}

Jangada | nr. 16, jun/dez, 2020 | ISSN 2317-47

144 | P á g in a 
d'autres références) communes parmi les auteurs et oeuvres. De plus, ces récurrences désignaient que les lectures étaient partagées et échangées entre les différents continents, ainsi que contribuaient avec la formation d'un certain goût culturel, d'après les choix des journalistes. Un parcours ressemblant est reconnu entre Eugène Pelletan, écrivain et journaliste français, et Machado de Assis. Tous les deux ont soutenu le journal comme un espace démocratique et libéral de transmission d'idées. À partir de cette ressemblance, l'on comparera les deux auteurs, afin de vérifier comment le sujet et les stratégies rhétoriques se rapprochent, configurant une pratique alors à la mode, et aussi comment cela s'éloigne, compte tenu des particularités de Machado de Assis.

MOTS-CLÉS : Machado de Assis, Eugène Pelletan, presse périodique, critique littéraire, progrès.

\section{INTRODUÇÃO}

A estreia de Machado de Assis na literatura e na imprensa periódica deu-se de modo concomitante, uma vez que seus primeiros poemas e artigos de crítica literária foram publicados nos jornais e revistas fluminenses em meados da década de 1850. Nesse sentido, era de se esperar que ambas as escritas se combinassem. Primeiro, porque esse era um movimento percebido entre os autores do século XIX, com o alto desenvolvimento do setor e a possibilidade de angariar a carreira literária a partir do jornalismo. Segundo, porque se tratava de um espaço profícuo para a formação do processo de escritura de um jovem literato.

Durante a análise realizada na tese A biblioteca de Machado de Assis na elaboração de sua crítica literária: os casos de Pelletan, Sainte-Beuve e Staël (2020), percebemos que, em um curto intervalo, - entre os anos de 1856, quando publicou a série de três artigos na seção "Ideias vagas" da Marmota Fluminense, e 1859, data do aparecimento de "O jornal e o livro" (Correio Mercantil), da coletânea "Aquarelas" e de "A reforma pelo jornal" (ambos da revista O Espelho), - várias mudanças aconteceram. A começar pelo tom entusiasmado e panfletário em defesa da literatura que, aos poucos, transformava-se em crítica e humor mais sutis. Consequentemente, os autores e obras com os quais mantinha intertextualidade também se modificaram, não só porque suas leituras se ampliavam, mas também porque os diversos nomes citados e aludidos em seus textos representavam papéis distintos, de acordo com suas intencionalidades. Por exemplo, em “A poesia”, há a seguinte epígrafe de Lamartine: “A poesia, como tudo que é divino, / não pode ser definida por uma palavra, / nem por mil. É a encarnação 
do que o homem / tem de mais divino no pensamento, do que a / natureza tem de mais magnífico / has imagens, de mais melodioso nos sons.” (LAMARTINE apud ASSIS, 2015, p. 976, v. 3).

Retirado de "Des destinées de la poésie", poema inserido no livro Méditations poétiques, esse excerto denota o caráter etéreo da poesia, cujo autor é um escolhido de Deus para a manifestação daquilo que há de mais belo e harmônico. Não à toa, a epígrafe de Lamartine aparece no primeiro texto de crítica literária de Machado de Assis, corroborando com o que este pensava a respeito do fazer poético: um dom divino de difícil definição; capaz, porém, de marcar tanto a alma abençoada do escritor quanto a do leitor sensível à arte, que deveria reconhecer e valorizar o trabalho daquele ainda em vida. Além de exaltar a missão espiritual da poesia, o jovem fluminense, ao se incluir no rol dos poetas sentimentais e emblemáticos, como era o caso de Lamartine, - entre outros nomes citados nesse mesmo artigo (André Chénier, Jean-Antoine Roucher, Nicolas Gilbert e Torquato Tasso), - pede a compreensão e solidariedade do público, para que o aceite e que sobre ele não recaia o mesmo destino dos quatro últimos poetas mencionados. Torna-se, assim, explícito em suas linhas finais: "Perdoai leitores, a minha fraca linguagem; é de um jovem que estreia nas letras, e que pede proteção e benevolência. Ainda existem alguns Mecenas piedosos: animai o escritor." (ASSIS, 2015, p. 977, v. 3).

Com essas informações do artigo "A poesia", destacamos o tom panfletário e entusiasmado que, aos poucos, foi se arrefecendo da escrita machadiana; outras estratégias aí presentes, todavia, foram amplamente empregadas, como é o caso da falsa modéstia que beira à ironia e do recurso intertextual como forma de apoiar suas ideias.

Segundo Jean-Michel Massa (2009), já em 1858 Machado se instalou definitivamente enquanto prosador. Em "O presente, o passado e o futuro da literatura” (A Marmota, 1858) é possível encontrar as principais reflexões que seriam desenvolvidas pelo crítico machadiano no desenrolar de sua trajetória em tal ofício. Vale notar que, por um lado, a escrita e os pensamentos sugeriam certo amadurecimento por parte do autor fluminense, tendo em vista a sua preocupação com a profissionalização do escritor na garantia dos direitos autorais e o papel imprescindível do crítico no que tange ao fazer literário. O título do artigo, por outro, mantém certo grau de idealismo, uma vez que, em poucas páginas, intencionava-se abordar vários séculos da literatura brasileira, na esperança de que a observação do passado e presente fosse capaz de mudar o rumo dos escritores e produções locais.

Para Massa, os textos já citados de 1859 colocam Machado em conflito, pois, na percepção daquele, a colaboração ativa deste na imprensa seria capaz de fazê-lo revogar sua 
carreira literária, devido a seu engajamento em questões políticas, sobretudo no que dizia respeito à participação do jornal.

A partir de estudos acerca da relação entre literatura e imprensa, tais como aqueles oriundos de Allain Vaillant (2001), Corinne Saminadayar-Perrin (2007) Dominique Kalifa (2011) e Marie-Ève Thérenty (2007), Lúcia Granja (2018) observou que percurso semelhante era traçado por Machado de Assis. A escritura literária, desse modo, combinava-se com os traços jornalísticos e vice-versa, pois ambos os universos passaram a conviver e a se coabitar. Percebe-se, com isso, a formação de uma poética compartilhada entre os jornalistas e literários ao longo do século XIX que, em muitos casos, chegou a atravessar o Oceano Atlântico. Exemplo disso é o cotejo que realizaremos entre textos de Machado de Assis e Eugène Pelletan.

\section{A POÉTICA JORNALÍSTICA DE EUGÈNE PELLETAN E MACHADO DE ASSIS}

Pierre-Clément-Eugène Pelletan (1813-1884), escritor e jornalista francês, estreou na imprensa parisiense em 1838 como colaborador de La Presse, de Émile de Girardin. Dentre os assuntos mais tratados por ele estão a crítica literária e artística, a política e as variedades da ordem do dia. Admirador e leitor assíduo de Lamartine e Victor Hugo, era defensor fervoroso do sistema republicano em pleno Segundo Império francês. Publicou diversos livros, sendo o primeiro deles La lampe éteinte (1840), romance de tese, no qual buscou mostrar que a imoralidade era um vício entre os jovens daquele século. Seus livros mais famosos, no entanto, não são literários e abordam a estreita relação entre imprensa, política e progresso: Profession de foi (1852) e Le monde marche (1857). Ambos, juntamente com Heures du travail (1854), chegaram ao Brasil no mesmo ano de sua publicação na França, segundo o registro bibliográfico do Diário do Rio de Janeiro. Além disso, citações e alusões de tais obras em jornais e revistas locais evidenciam que o autor era largamente conhecido pelos brasileiros.

De acordo com Jean-Michel Massa, tratava-se de "um dos mestres do pensamento do século XIX" que

[...] substituiu, no espírito de Machado de Assis, a influência dos astros que declinavam: Chateaubriand e Lamartine. O publicista Pelletan lhe abriu um novo mundo, cheio de perspectivas, e o fez viajar na filosofia das religiões. Homem de vastas sínteses, Pelletan abarcava de um só relance o passado, o presente e o futuro. Outros dirão sobre o valor de sua visão de mundo, mas 
seu sincretismo generoso de ideias, em que misturava tumultuosamente todos os domínios do conhecimento, seduzira então numerosos espíritos eminentes. Machado de Assis, sensível ainda a todas as correntes, encontrou nele uma fé ardente e talvez uma resposta a algumas das questões que a si mesmo colocava. (MASSA, 2009, p. 190)

Para ilustrar a análise do crítico francês, no início de "O jornal e o livro", logo após exaltar Le monde marche, de Pelletan, Machado faz uma alusão a Lamartine, seguida de alguns questionamentos retóricos:

A Revolução Francesa, o estrondo maior dos tempos europeus, na bela expressão do poeta de Jocelyn, foi o passo da humanidade para entrar neste século. O pórtico era gigantesco, e era necessário um passo de gigante para entrá-lo. Ora, a explosão do pensamento humano concentrado na rainha Europa não é um sintoma de progresso? O que era a Revolução Francesa senão a ideia que se fazia República, o espírito humano que tomava a toga democrática pelas mãos do povo mais democrático do mundo? (ASSIS, 2015, p. 991, v. 3)

A princípio, o autor fluminense parece elogiar Lamartine, uma vez que se refere ao seu texto como "bela expressão". Ao entrar em contato com o conteúdo de Le monde marche, como faremos, observamos a ambiguidade dessa consideração, pois, ao mesmo tempo em que o crítico faz um comentário positivo sobre a escrita do poeta francês, as interrogativas propostas na sequência revelam a sua tomada de posição ao lado de Pelletan, que compôs uma obra destinada a Lamartine a fim de convencê-lo sobre sua ideia acerca do progresso, com a qual este último não compactuava. Se, em 1856, Lamartine era considerado por Machado como exemplo de poética, em 1859, os pensamentos daquele passavam a ser questionados por este, tendo sob perspectiva a leitura que realizava de Eugène Pelletan.

Essa transformação no posicionamento machadiano ocorre, portanto, quando ele começa a se engajar na discussão sobre o papel da imprensa na formação de uma intelectualidade local. Em 1858, no Correio Mercantil, o autor fluminense publicou o poema "O progresso: hino da mocidade", dedicado ao escritor francês e com epígrafe em latim ("E pur si muove"), retirada do livro Le monde marche.

Espécie de ode, "O progresso" é composto por treze estrofes de quatro versos alexandrinos cada uma, sendo que o seguinte estribilho se repete a cada terceto: "Ao som da 
tua voz a mocidade acorda / E olha ousada de face os plainos do porvir! / Eia! Rebenta a flor da longa estrada à borda, / E através do horizonte há uma aurora a rir!” (ASSIS, 2015, p. 714, v.3). Esse refrão explicita o teor do poema, que apresenta Pelletan como um mestre da modernidade, cuja voz é ouvida pela nova geração, mais ousada e ávida por mudanças, rumo ao progresso da humanidade. Para tanto, são recorrentes no texto machadiano termos e imagens indicando um novo ciclo e um caminho a perseguir, para conquistar o futuro que já se encontrava visível no horizonte, graças às orientações do publicista francês.

O mesmo assunto é retomado por Machado de Assis em "O jornal e o livro", também publicado no Correio Mercantil, em 1859, com a alusão a Le monde marche, de Eugène Pelletan, definido como um "livro de ouro, que tornou-se o Evangelho de uma religião" (ASSIS, 2015, p. 991, v. 3). A partir do recurso retórico da falsa modéstia, que se alinha ao conteúdo do artigo, o autor se coloca como um dos últimos e "menos inteligentes adeptos" da crença no progresso humano. Fez referência, assim, ao seu poema publicado no ano anterior, como maneira de manifestar a sua "profissão de fé". Observamos, dessa forma, que a escritura de seu texto muito se assemelhava à linguagem utilizada por Pelletan, em Le monde marche. O jovem fluminense, portanto, não abandonava a sua fé na vocação divina da poesia; transferia-a para outro deus: o progresso, cujo porta-voz era Pelletan.

Le monde marche leva como subtítulo "lettres à Lamartine", buscando o poeta francês enquanto interlocutor. Logo no prefácio, dedicado ao filósofo e sociólogo Jean Reynaud, Pelletan sinaliza o seu descontentamento com o Troisième Entretien de Littérature, de Lamartine:

O mestre mantinha-se em silêncio. O discípulo tomou a palavra. Talvez ele tivesse um certo direito de tomá-la sem ter pedido autorização, por ter o primeiro suspeitado, na Profession de Foi du XIX siècle, da fórmula do progresso crescimento de vida; de vida física com mais forças, de vida moral com mais sentimentos, de vida intelectual com mais conhecimentos. (grifos do original; tradução nossa) ${ }^{2}$

O progresso é apresentado por Pelletan como um processo contínuo, principiado com a criação da Terra e sucedido por todos os acontecimentos posteriores. Desse modo, o

\footnotetext{
${ }^{2}$ No original, lê-se: "Le maître gardait le silence. Le disciple a pris la parole. Peut-être avait-il quelque droit à la prendre d'office, pour avoir soupçonné le premier, dans la Profession de Foi du XIXe siècle, la formule du progrès accroissement de vie; de vie physique par plus de forces, de vie morale par plus de sentiments, de vie intellectuelle par plus de connaissances." (PELLETAN, 1858, p. IV)

Jangada | nr. 16, jun/dez, 2020 | ISSN 2317-47 149 | P á g i n a
} 
surgimento de novas espécies de seres vivos ou mesmo de minerais, cada descobrimento e invenção humana, enfim, cada mínimo detalhe contribuiria para que a vida estivesse em constante movimento e, este, por sua vez, apontava para a sua evolução. O progresso nessa concepção, todavia, não é trilhado em linha reta; há em seu percurso desvios, lacunas e retornos. Por isso, ele não é entendido somente quando há conquistas positivas, mas sim a partir de todas as consequências necessárias para se chegar a um fim. Pelletan, portanto, acreditava que da mesma forma que houve um início, na Terra, haveria também seu término, assim que alcançássemos a perfeição.

Em resposta às provocações de seu discípulo, Lamartine afirma não ser um completo descrente do progresso. Ele acreditava que havia um avanço humano e relativo, porém, não interpretava cada ação sobre a Terra de maneira indefinida e contínua, conforme o autor de $L e$ monde marche. Inconformado com o posicionamento de seu mestre, Eugène Pelletan escreve seu livro, reunindo diversos exemplos retirados dos mais variados campos do conhecimento, a fim de que sua argumentação seja suficiente para convencer o seu interlocutor.

Segundo Édouard Petit (1913), a visão divergente de ambos os escritores franceses se dá através do reflexo de suas percepções de mundo. De um lado, a impaciência do poeta mostrase insatisfeita com as desilusões da vida, que não atende prontamente às necessidades e ao direito à felicidade do ser humano. De outro, o jornalista, com seu perfil mais filosófico, entende que as consequências negativas são tão importantes quanto as positivas para provar a existência do progresso. Para fazer frente aos contra-argumentos de Lamartine, Pelletan explana: "Todas as civilizações estão mortas, você diz. O fato é verdadeiro, eu concordo. Mas a civilização em si sobreviveu, e ela sobreviveu justamente porque era a razão comum de todas as metamorfoses da história" (tradução nossa). ${ }^{3}$

Com isso, o autor de Le monde marche elenca uma série de conquistas humanas, tais como a lâmpada, o navio, a escrita, o domínio das ciências, entre tantas outras arroladas por ele, para mostrar que, apesar das civilizações egípcia, fenícia, grega e romana terem sucumbido, seus feitos se espalharam pelo mundo todo e continuam sendo usados, agora, por outros povos, para que o avanço nunca seja interrompido, uma vez que ele é a ordem superior da natureza.

De modo semelhante, estrutura-se "O jornal e o livro", dedicado ao escritor Manuel Antônio de Almeida, apesar da enorme diferença de extensão entre um texto e outro. Após

\footnotetext{
${ }^{3}$ No original, lê-se: "Toutes les civilisations sont mortes, dites-vous. Le fait est vrai, j'en conviens. Mais la civilisation elle-même a survécu, et elle a survécu précisément parce qu'elle était la raison commune de toutes les métamorphoses de l'histoire." (PELLETAN, 1858, p. 212)
} 
demonstrar estar de acordo com Pelletan no que se refere à perfectibilidade humana - espécie de sol que norteia o espírito humano - Machado inicia o seu processo de argumentação. Para comprovar a premissa de que "A humanidade desde os primeiros tempos tem caminhado em busca de um meio de propagar e perpetuar a ideia" (ASSIS, 2015, p. 992, v. 3), ele exemplifica de que maneira a arquitetura, em primeiro lugar, e o livro, em segundo, eram os veículos destinados a esse fim, que, então, cedia lugar ao jornal. Cada uma dessas conquistas humanas, dessa forma, teve a sua primazia substituída pela sua sucessora:

Era, porém, preciso um gigante para fazer morrer outro gigante. Que novo parto do engenho humano veio nulificar uma arte que reinara por séculos? Evidentemente era mister uma revolução para apear a realeza de um sistema; mas essa revolução devia ser a expressão de um outro sistema de incontestável legitimidade. Era chegada a imprensa, era chegado o livro. (ASSIS, 2015, p. 992, v. 3)

Nesse excerto, observamos a predominância da tipologia narrativa, assim como ocorre em outros trechos do artigo "O jornal e o livro", com a sucessão de acontecimentos que marcam o fim do império da arquitetura e o fortalecimento da imprensa, a qual assume, então, o posto de preservar a expressão da ideia humana. Essa construção textual, ao lado das metáforas, chama a atenção para a hibridez entre literatura e jornalismo; processo muito semelhante é percebido na composição de Le monde marche.

Soma-se a isso o pensamento compartilhado entre ambos os escritores a respeito do tema. Machado, portanto, defende: “A lei eterna, a faculdade radical do espírito humano, é o movimento. Quanto maior for esse movimento mais ele preenche o seu fim, mais se aproxima desses polos dourados que ele busca há séculos" (ASSIS, 2015, p. 993, v. 3). É nesse sentido que, ainda que o livro sucumbisse ao jornal, esse era o preço a ser pago (e até aceitável) para que a revolução fosse completa e a imprensa periódica, enfim, pudesse cumprir com o seu papel: tornar o pensamento humano acessível a todas as classes econômicas e sociais, haja vista que

O jornal é a verdadeira forma da república do pensamento. É a locomotiva intelectual em viagem para mundos desconhecidos, é a literatura comum universal, altamente democrática, reproduzida todos os dias, levando em si a frescura das ideias e o fogo das convicções. (ASSIS, 2015, p. 993, v. 3) 
A dinamicidade das ideias e a possibilidade de debatê-las amplamente enquanto ainda estavam em efervescência foram os aspectos positivos do jornal que Machado de Assis destacou com relação ao livro, que, por ser estático, encerrava em si uma opinião. Ambos produzem conhecimento; este, no entanto, contempla informações do passado, ao passo que aquele preocupa-se, sobretudo, com o presente.

O movimento como "lei eterna" da humanidade, ademais, é a premissa do livro de Eugène Pelletan, conforme o próprio título da obra já adianta: Le monde marche. No português brasileiro, o verbo "marche" em francês pode ter várias traduções: "marcha", "caminha" ou "anda". Quanto à conjugação, duas formas são possíveis: o presente gramatical e imediato ("marcha", "caminha" ou "anda") e o gerúndio, utilizado no Brasil para substituir o presente (“está marchando", "está caminhando" ou "está andando"). No primeiro caso, o presente indica uma verdade universal, como acontece nas máximas. Já no segundo, o gerúndio pressupõe uma ação que se desenrola no momento da enunciação e que tem continuidade. Em ambas as traduções, ou mesmo no uso original do termo, há o intuito de mostrar que o mundo se movimenta constantemente, porque essa é uma ordem superior da natureza que não irá cessar.

Além da temática e ponto de vista compartilhados, notamos retórica semelhante entre os dois escritores. É possível encontrar, para tal fato, ao menos duas justificativas. A primeira delas, de âmbito particular, diz respeito ao desenvolvimento da escrita machadiana. A segunda, de caráter geral, chama a atenção sobre uma poética comum aos escritores do século XIX que também colaboravam na imprensa periódica. Tanto uma quanto a outra explicação elucidam o processo de formação do crítico literário brasileiro, ao lado do poeta, jornalista e iminente prosador.

A fim de ilustrar essas semelhanças, destacamos os seguintes excertos:

E a voz, o que ela é? Um som. Nada mais, a princípio. O homem articula o som, e eis a palavra; ele a cadencia, e eis a poesia; e Orfeu, um dia, mantém, ao redor dele, a humanidade comovida suspensa na atmosfera devido à vibração de sua lira. Porém, palavra articulada ou palavra ritmada nunca é apenas uma explosão do lábio. O vento a ouve, o vento a leva. Então, o progresso fixa a sílaba errante sobre a folha de papiro com um sinal, e a folha carregada do pensamento de todo o gênio humano voa no ar do tempo pendendo indefinidamente de geração em geração. Mas o que é a escritura? Uma palavra ainda lenta, dispendiosa, limitada a um pequeno número de eleitos. Guttenberg encontra em sua genialidade o segredo de negociar a letra 
de alguma forma e, a partir desse dia, a imprensa dá à voz humana uma tal ondulação que ela mal diz uma palavra e essa palavra ressoa instantaneamente por todos os cantos do universo. (tradução nossa) ${ }^{4}$

O que era a imprensa? Era o fogo do céu que um novo Prometeu roubara, e que vinha animar a estátua de longos anos. Era a faísca elétrica da inteligência que vinha unir a raça aniquilada à geração vivente por um meio melhor, indestrutível, móbil, mais eloquente, mais vivo, mais próprio a penetrar arraiais de imortalidade. (ASSIS, 2015, p. 992, v. 3)

Nos dois trechos, verificamos a existência de uma pergunta retórica introduzindo o parágrafo, que continua com explanações alegóricas indicativas do desenvolvimento civilizatório de determinado conceito, tendo como fim o progresso humano. Nesse caso, ambos exaltam a criação da imprensa e o poder da transmissão das palavras, que, transformadas em livros, perpetuam-se. Mais uma vez, os autores fazem uso de estratégias narrativas, apontando o percurso trilhado até se chegar à conquista almejada. Digressivo, o excerto de Pelletan reconta, de maneira resumida, como o som se tornou palavra e esta serviu de matéria-prima para a comunicação da humanidade. Já Machado é mais direto na descrição e adjetivação da imprensa livreira. Conjecturamos, desse modo, que tais conceitos (som, palavra e imprensa) funcionam como personagens dessa breve história. Os dois fragmentos, ademais, evidenciam a participação, ora efetiva, ora alusiva, de seres mitológicos nessa conquista, a fim de mostrar a importância e grandiosidade de tais feitos.

O mesmo assunto e estilo são ampliados em outro artigo de Machado, “A reforma pelo jornal", publicado ainda em 1859 na revista $O$ Espelho:

Ora pois, a palavra, esse dom divino que fez do homem, simples matéria organizada, um ente superior na criação, a palavra foi sempre uma reforma. Falada na tribuna é prodigiosa, é criadora, mas é o monólogo; escrita no livro,

\footnotetext{
${ }^{4}$ Lê-se no original: "Et la voix; qu'est-elle? un son. Rien de plus au commencement. L'homme articule le son, et voici la parole; il le cadence, et voici la poésie; et Orphée tient un jour l'humanité suspendue à l'atmosphère émue autour de lui de la vibration de sa lyre. Mais, parole articulée ou parole rhythmée, ce n'est jamais qu'une explosion de la lèvre. Le vent l'entend, le vent l'emporte. Alors le progrès fixe d'un signe la syllabe errante sur la feuille de papyrus, et la feuille chargée de la pensée du génie humain tout entier et envolée au souffle du temps retombe indéfiniment de génération en génération. Mais qu'est-ce l'écriture ? une parole encore lente, dispendieuse, limitée à un petit nombre d'élus. Guttenberg trouve dans son génie le secret de monnoyer la lettre en quelque sorte, et à partir de ce jour la presse donne à la voix humaine une telle ondulation, qu'à peine a-t-elle dit un mot, que ce mot retentit instantanément partout à la fois sur l'univers." (PELLETAN, 1857, p. 107-8)
} 
é ainda criadora, é ainda prodigiosa, mas é ainda o monólogo; esculpida no jornal, é prodigiosa e criadora, mas não é o monólogo, é a discussão.

E o que é a discussão?

A sentença de morte de todo status quo, de todos os falsos princípios dominantes. Desde que uma coisa é trazida à discussão, não tem legitimidade evidente, e nesse caso o choque da argumentação é uma probabilidade de queda. (ASSIS, 2015, p. 1018, v. 3)

Dessa vez, para provar a superioridade do jornal em relação ao livro e ao discurso, o articulista se refere à palavra enquanto um presente de Deus. Ela só tem eficácia garantida, porém, ao se tornar discussão, quando um grupo de pessoas de diferentes pensamentos e origens pode debater as diversas opiniões. O jornal, desse modo, era responsável por manter acesa uma chama alimentada com fogo vindo dos mais variados lugares. Na concepção machadiana, a imprensa periódica colocaria os assuntos relativos à constituição de nossa pátria, seja no âmbito econômico, social ou artístico, em evidência, fazendo com que as ideias e os planos fossem arquitetados e o país, assim, progredisse. Além do mais, em sua visão, as classes proletárias eram as que tinham os instrumentos para fazer a reforma necessária no Brasil. E, nesse sentido, colocou-se contrário à permanência das aristocracias no poder, pois acreditava que o momento era propício para o desenvolvimento coletivo e não individual.

Já em "O jornal e o livro", Machado se pronunciava a esse respeito: "A humanidade, antes de tudo, é republicana" (ASSIS, 2015, p. 991, v. 3). Não queremos dizer, com isso, que Machado era um republicano; mas sim que, em 1859, ele percebia que o sistema aristocrático estava ultrapassado, na medida em que a república se apresentava como o seu progresso, encorajada pelo espírito democrático que o jornal propiciava.

Para argumentar o seu ponto de vista, o escritor fluminense, em "A reforma pelo jornal”, examina:

A primeira propriedade do jornal é a reprodução amiudada, e o derramamento fácil em todos os membros do corpo social. Assim, o operário que se retira do lar, fatigado pelo labor quotidiano, vai lá encontrar ao lado do pão do corpo, aquele pão do espírito, hóstia social da comunhão pública. A propaganda assim é fácil; a discussão do jornal, reproduz-se também naquele espírito rude, com a diferença que vai lá achar o terreno preparado. A alma torturada da individualidade ínfima, recebe, aceita, absorve sem labor, sem obstáculos aquelas impressões, aquela argumentação de princípios, aquela arguição de 
fatos. Depois uma reflexão, depois um braço que se ergue, um palácio que se invade, um sistema que cai, um princípio que se levanta, uma reforma que se coroa. (ASSIS, 2015, p. 1018, v. 3)

Acessível a todas as camadas da população, o jornal entra na casa do trabalhador comum com informações que despertam a sua consciência e promovem nele o desejo de mudança. Uma das consequências possíveis desse processo é o estabelecimento de um novo regime governamental. Ao afirmar que "um palácio que se invade, um sistema que cai”, fica implícita a substituição do poder aristocrático pelo republicano. Antes dessa transformação acontecer, no entanto, ela precisa ser introduzida no espírito do cidadão enquanto necessidade que urge ser concretizada: eis o papel central que a imprensa periódica realizava na vida social, econômica, política e cultural de um país. A partir disso, Machado defende que o progresso é a busca por uma melhor condição da existência, conduzindo a humanidade às modificações necessárias para tal fim.

Ideia semelhante encontra-se na obra de Pelletan, ao designar a democracia como sendo o avanço do absolutismo; em primeiro lugar, porque possibilitava ao povo ser livre e, a partir dessa liberdade, enfim, o caminho para o progresso estava aberto. Logo no início do livro, ao estabelecer o diálogo com seu interlocutor, o publicista francês o questiona, deixando claro o seu posicionamento acerca dos regimes políticos, sendo um a sucessão esperada do outro rumo ao avanço da humanidade: "Você ouviu a voz do ar, e ao sinal dessa voz, passou do dogma da realeza ao dogma da democracia. Se isso ainda não é um progresso, então, o que é o progresso?" (tradução nossa). ${ }^{5}$ Nesse trecho, percebemos uma alusão implícita aos desdobramentos da Revolução Francesa, durante a qual o próprio Lamartine teve uma mudança abrupta, pois passou de membro da aristocracia para defensor da república. Essa transformação é entendida por Pelletan como um sintoma de progresso; a mesma interpretação é reaproveitada por Machado de Assis, como vimos.

Em Le monde marche, afirma ainda que apesar de a inteligência ter feito o homem superior aos outros animais, ela só existia, de fato, auxiliando em seu progresso, se construída dentro de uma civilização que trabalhasse coletivamente. O ser humano, conforme Pelletan, nasceu ínfimo, assim como Adão no Paraíso. É o seu contato com outros seres e aquilo que eles são capazes de desenvolver juntos que faziam o mundo avançar.

\footnotetext{
${ }^{5}$ No original, lê-se: "Vous avez entendu la voix de l'air, et au signal de cette voix vous avez passé du dogme de la royauté au dogme de la démocratie. Si ce n'est pas là encore un progrès, qu'est-ce donc le progrès ?" (p. 5-6)
}

Jangada | nr. 16, jun/dez, 2020 | ISSN 2317-47 155 | P á g i n a 
Os questionamentos e as construções eloquentes nos excertos transcritos, que se aproximam de máximas, bem como os exemplos didáticos e metafóricos apontam para o interdiscurso entre Machado de Assis e Eugène Pelletan. Além das aproximações retóricas, o pensamento liberal e democrático a respeito do jornal é compartilhado por ambos, de modo a supor que "O jornal e o livro" empreende uma espécie de pastiche de Le monde marche, a qual é reutilizada em "A reforma pelo jornal”.

Segundo Thiphaine Samoyault (2008), o pastiche consiste na imitação de um estilo com o objetivo de deformá-lo, de modo que o hipertexto (o texto imitado) não costuma ser evocado no hipotexto (a imitação). É como se o autor do pastiche quisesse brincar com o leitor, fazendo com que este reconheça em sua obra a presença de um estilo, talvez, mais refinado, ou simplesmente conhecido do público. A intenção de Machado não era satírica, tampouco ele desejou esconder sua aproximação com Le monde marche; sendo assim, podemos interpretar “O jornal e o livro" e, em certa medida, "A reforma pelo jornal”, como casos de pastiche, pois "[...] ao se imitar um autor, não somente se aprende a escrever, mas libera-se [sic] também das influências mais ou menos conscientes que se pode ter sobre seu próprio estilo" (SAMOYAULT, 2008, p. 55).

Ainda, segundo Frederic Jameson (1995, p. 29), ao contrário da paródia, o pastiche é uma espécie de imitação neutra de um "estilo peculiar ou único" que não busca, portanto, o riso ou a crítica, mas apenas uma aproximação com a escrita e as ideias de outro autor.

Considerando a pouca experiência de prosador de Machado a essa altura, iniciado na carreira havia apenas três anos, com esparsos artigos publicados, a ideia de imitar um estilo pelo qual havia se encantado e que transmitia verdades capazes de convertê-lo a uma nova religião parece-nos bastante provável. Também é essa a opinião de Jean-Michel Massa, para quem "O jornal e o livro" é "[...] uma síntese apaixonada, em que se misturam o pensamento de Pelletan e a eloquência de Hugo" (MASSA, 2009, p. 192). Ressaltamos, com isso, que o folhetim de 1859 apresenta-se como uma espécie de homenagem ao autor de Profession de foi, tendo em vista o seu local de destaque na fermentação dos ideais liberais acerca da imprensa, fundamentais para o desenvolvimento do jornalista machadiano. As reflexões tiradas de sua leitura de Le monde marche, dessa forma, repercutirão em suas obras da década seguinte.

Uma observação atenta a tais informações, portanto, faz-se fundamental para não só entendê-las, mas também para analisar como se deu a sua formação intelectual e de que maneira ela influenciava em sua escrita. Não queremos, de forma alguma, indicar uma suposta inferioridade do jornalista brasileiro com relação ao francês; acreditamos, porém, que para 
posicionar-se com autonomia, foi necessário àquele muito estudo e ponderação, para que fosse capaz de distinguir, entre tantas vozes, aquela que lhe parecesse própria.

Conforme explana Jose-Luis Diaz (2007), em L'écrivain imaginaire, o período romântico viveu a antropologização do autor, entendido não como um "ser no mundo", mas sim enquanto "instância nominal" que se dirigia a si mesmo por meio da autorrepresentação ou que inscrevia seu nome em suas obras. Todo escritor, desde o início de sua carreira, sente a necessidade de criar uma imagem, tanto para que o leitor o identifique, quanto para conseguir enxergar a si próprio. Por isso, é comum que os ingressantes elejam suas preferências literárias e comecem a imitá-las, menos devido a influências textuais e mais graças a certo "mimetismo comportamental" (DIAZ, 2007, p. 109). No caso de Machado de Assis, poeta havia cerca de cinco anos e crítico havia três, era preciso que se definisse a sua condição de homem de letras. De acordo com Diaz, este deixa de ser uma construção apenas textual, tal como aquela de autor, para se tornar uma personagem real, ao mesmo tempo "sujeito biográfico" e "ator social" (DIAZ, 2007, p. 17-8).

É interessante observar que a leitura de Le monde marche não se restringiu ao desenvolvimento das ideias machadianas no que tangia às suas considerações acerca da literatura; ela também ressoou em sua poesia, como pudemos perceber com o poema "Hino da mocidade". Emprestar a voz de Pelletan, sendo assim, a fim de encorpar o coro de suas convicções, propõe-se enquanto estratégia para que o público o reconheça semelhante ao jornalista francês, mais experiente do que o brasileiro, contribuindo, então, para a criação de uma identidade, através da qual se intenciona ser visto.

Além do mais, como já mencionado, pesquisas recentes acerca da relação entre imprensa e literatura oitocentistas têm mostrado que o intercâmbio de formas e assuntos entre uma e outra afetava tanto as produções textuais quanto os modos de vida de autores e dos cidadãos no geral, ao menos aqueles residentes nos centros urbanos por onde o jornal transitava. É possível, a partir dessas considerações, afirmar a existência de uma poética jornalística (entre outras desenvolvidas concomitantemente), compartilhada pelos colaboradores dos periódicos, de modo que os intertextos, por exemplo, eram reincidentes e a própria escrita adquiria certo aspecto reconhecível como característico daquele determinado meio. Sob esse ponto de vista, Pelletan representava uma das várias formas de escrita jornalística amplamente empregada no século XIX, na qual Machado gostaria de se inserir, pelo menos até conquistar o seu próprio espaço. 


\section{CONSIDERAÇÕES FINAIS}

Os primeiros textos de crítica literária de Machado de Assis, escritos na segunda metade da década de 1850, aproximam-se, uns mais do que outros, do gênero ensaístico, tendo em vista a intenção de tecer comentários acerca de uma ideia que se constrói subjetivamente e é, aos poucos, apresentada ao leitor, chegando a conclusões de maneira original. O estilo empregado pelo jovem fluminense é, mais tarde, aprofundado em suas crônicas. Apesar disso, desde então se percebe a sua característica de introduzir o tema, de modo sorrateiro e com um ar despretensioso, mas que, paulatinamente, vai crescendo em significação. Esse jeito machadiano, muito explorado ao longo de sua trajetória, foi por ele próprio confessado no famoso "O nascimento da crônica", quando teorizou sobre o gênero literário em questão, compondo um exemplo exato daquilo que explanava. Além do mais, esse caráter, a princípio, despreocupado, que, pouco a pouco, ganha em complexidade, é também apontado como essencial para a constituição da crônica em "A vida ao rés-do-chão", de Antonio Candido (1982).

O progresso, pedra de toque de Eugène Pelletan, é por ele apresentado como algo que se constrói a passos lentos e cujo êxito estaria relacionado diretamente a algumas renúncias necessárias, para que houvesse mudanças pertinentes na sociedade. Nessa perspectiva, é possível aceitá-lo ou negá-lo, e quando escolhida a primeira opção, deve-se buscar entender o progresso enquanto lei suprema que move a humanidade. Devido a essa crença, o jornalista francês termina seu livro apontando a dualidade de Lamartine no que se refere aos seus princípios. Um poeta de sua estirpe, tanto pela sua aura no imaginário francês quanto por sua contribuição efetiva na vida cultural e política de seu país, deveria render-se ao avanço social. A postura contrária de Lamartine, no entanto, fez com que a sua queda, na concepção de Pelletan, fosse tão grande quanto a sua glória.

Além do mais, o progresso em Le monde marche aparece como uma ideia que, aos poucos, torna-se complexa. Da evolução natural da vida para a constituição das civilizações, a humanidade tende a caminhar em direção a Deus, nas palavras do jornalista francês. Seja no espectro físico ou espiritual, o autor afirma que a terra um dia acabará, mas não antes de atingirmos a perfeição e, por isso, aceitar o progresso é também concretizar os planos divinos.

É interessante notar a formação do jovem Machado de Assis escritor e intelectual. Antes mesmo de sua leitura de Le monde marche, o autor fluminense deu mostras de sua crença na poesia enquanto veículo das palavras de Deus. Após conhecer o livro de Pelletan, o qual faz 
muitas alusões à fé cristã, vimos o tom religioso sumir, paulatinamente, dos textos machadianos, ao passo que parecia se encantar, sobretudo, com as obras humanas, como a imprensa periódica.

A própria ideia de progresso é percebida com algumas diferenças por ambos os escritores. Embora os dois o entendam como um movimento de partida da humanidade, o ponto de chegada mostra-se distinto. Para Eugène Pelletan, o progresso é o caminho que leva o homem à perfeição, objetivo este, portanto, nunca inteiramente alcançado, mas sempre perseguido.

Sob tal perspectiva, o progresso transforma o homem em um ser imortal; na medida em que os seus feitos são passados para as próximas gerações, ele se perpetua através de seu legado. O ser humano, então, não é visto como uno, movido só pelos desejos individuais, mas como parte de um organismo que, até mesmo sem consciência, contribui para se chegar a determinado fim coletivo, ainda que este não signifique, necessariamente, a obtenção de um bem positivo. Avanço e recuo, nesse sentido, são movimentos de mesma importância, pois o propósito almejado é desconhecido e, assim, indefinido.

Já na visão de Machado de Assis, o progresso era sinônimo de imprensa periódica, sendo esta compreendida como uma possibilidade para a jovem nação brasileira se desenvolver. A resposta encontrada pelo autor fluminense, portanto, não recaía sobre a ciência, tal como era para Pelletan, mas sobre o domínio da palavra.

Ao se tornar acessível à toda a população, o jornal tem o poder de ser o "gérmen de uma revolução", a que Machado se referia em "O jornal e o livro", a qual, segundo continua no artigo do Espelho, só se deve esperar das “inteligências proletárias”. Se dependesse das classes superiores, detentoras do poder, não haveria transformação, em outras palavras, progresso. As mudanças na ordem social devem servir para aproximar a humanidade de uma melhor existência. Para isso, a imprensa ocupa o lugar central, pois através dela a reforma do status quo seria possível, a partir de uma ideia que se difunde e instaura a insatisfação nos cidadãos.

Eugène Pelletan e Machado de Assis eram colaboradores da imprensa periódica que se aproveitaram desse espaço para elaborar e desenvolver sua escritura, assim como procederam tantos outros homens de letras do Oitocentos. Por questões de ordem editorial e pessoal, o autor brasileiro não compilou em livro suas crônicas e demais textos jornalísticos, apenas o fez com suas produções mais puramente literárias, por falta de melhor termo. Diferentemente disso, o escritor francês, além de participar de maneira ativa dos jornais, também publicava volumes de semelhante teor. De qualquer modo, os dois escritores fizeram com que ambos os suportes, 
jornal e livro, pudessem ser lidos um como a ramificação do outro. A linguagem coincidente proporcionou, com isso, uma constante renovação nos estilos jornalístico e literário, praticada durante o século XIX nos mais diferentes países. Conforme demonstramos, o tema e a poética eram recorrentes, bem como as referências intertextuais, como é o caso de Lamartine, citado por Pelletan e Machado como o grande mestre da poesia romântica ocidental, mas que teve seu posicionamento cético acerca do progresso questionado.

\section{REFERÊNCIAS BIBLIOGRÁFICAS}

ASSIS, J. M. Machado de. Obra completa em quatro volumes. São Paulo: Nova Aguilar, 2015. AZEVEDO, Sílvia M.; DUSILEK, Adriana; CALLIPO, Daniela M. (Orgs.). Machado de Assis: crítica literária e textos diversos. São Paulo: UNESP, 2013.

CANDIDO, Antonio. A vida ao rés-do-chão. In: ANDRADE, Carlos Drummond de et al. Para gostar de ler: crônicas. São Paulo: Ática, 1982, v. 5, p. 5-23.

DIAZ, José-Luiz. L'écrivain imaginaire: scénographies auctoriales à l'époque romantique. Paris: Honoré Champion, 2007.

GRANJA, Lúcia. Machado de Assis - Antes do livro, o jornal. Suporte, mídia e ficção. São Paulo: Unesp, 2018.

JAMESON, Fredric. Espaço e imagem: teoria do pós-moderno e outros ensaios. Rio de Janeiro: Editora UFRJ, 1995.

KALIFA, Dominique; et al. La civilisation du journal. Une histoire de la presse française au XIX ${ }^{\mathrm{e}}$ siècle. Paris: Nouveau Monde, 2011.

MASSA, Jean Michel. A juventude de Machado de Assis: 1839-1819. Prólogo de Antonio Candido.Tradução de Marco Aurélio de Moura Matos. $2^{\text {a }}$ ed. rev. São Paulo: UNESP, 2009. MUSSULINI, Dayane. A biblioteca de Machado de Assis na elaboração de sua crítica literária: os casos de Pelletan, Sainte-Beuve e Staël. 2020. Tese (Doutorado em Letras) Universidade Estadual Paulista (UNESP), Faculdade de Ciências e Letras, Assis, 2020.

PELLETAN, Eugène. Le monde marche: lettres à Lamartine. 2 ed. rev. e corr. Paris: Pagnerre, 1858. (Gallica).

Profession de foi du XIX ${ }^{e}$ siècle. 6 ed. Paris: Pagnerre, 1864. (Gallica).

PETIT, Edouard. Eugène Pelletan, 1813-1884, l'homme et l'oeuvre: d'après des documents inédits. Pref. De Ferdinan Buisson. Paris: Aristide Quillet, 1913. (Gallica) 
SAMOYAULT, Tiphaine. A intertextualidade. Tradução Sandra Nitrini. São Paulo: Hucitec, 2008 .

SAMINADAYAR-PERRIN, Corinne. Les discours du jornal. Rhétorique et médias au XIX siècle (1836-1885). Saint-Étienne: Publications de l’Université de Sainte-Étienne, 2007.

THÉRENTY, Marie-Ève. La littérature au cotidien : poétiques journalistiques au XIX ${ }^{\mathrm{e}}$ siècle. Paris: Seuil, 2007.

. «Pour une histoire littéraire de la presse au $\mathrm{XIX}^{\mathrm{e}}$ siècle ». Revue d'histoire littéraire de la France. 2003/3 (Vol. 103), p. 625-635.

THÉRENTY, Marie-Ève; VAILLANT, Alain. L'An I de l'ère médiatique. Analyse littéraire et historique de La Presse de Girardin. Paris: Nouveau Monde, 2001. 